\title{
Cr-Dy-Fe (Chromium-Dysprosium-Iron)
}

\section{Raghavan}

Recently, [2009Yao] determined an isothermal section for this system at $500{ }^{\circ} \mathrm{C}$ which depicts a ternary compound $\mathrm{DyFe}_{10} \mathrm{Cr}_{2}(\tau)$.

\section{Binary Systems}

There are no intermediate phases in the Cr-Dy system [Massalski2]. The mutual solubility between $\mathrm{Cr}$ and Dy is small. In the Fe-Cr phase diagram [1993Itk], a gamma loop restricts the fcc region to about 14 at.\% $\mathrm{Cr}$. The bcc $\alpha$ phase is stable over a large region. The intermediate phase $\sigma$ ( $D 8_{b}$-type tetragonal) forms from $\alpha$ at $820{ }^{\circ} \mathrm{C}$ around the mid-composition and decomposes eutectoidally at $545{ }^{\circ} \mathrm{C}$ to Fe-rich bcc $(\alpha)$ and Cr-rich bcc $\left(\alpha^{\prime}\right)$ phases. The Fe-Dy phase diagram [Massalski2] depicts the following intermediate phases: $\mathrm{Fe}_{17} \mathrm{Dy}_{2}\left(\mathrm{Ni}_{17} \mathrm{Th}_{2}\right.$-type hexagonal), $\mathrm{Fe}_{23} \mathrm{Dy}_{6}$ ( $D 8_{a}, \mathrm{Mn}_{23} \mathrm{Th}_{6}$-type cubic), $\mathrm{Fe}_{3} \mathrm{Dy}\left(\mathrm{Be}_{3} \mathrm{Nb}\right.$-type rhombohedral), and $\mathrm{Fe}_{2} \mathrm{Dy}\left(\mathrm{C} 15, \mathrm{MgCu}_{2}\right.$-type cubic).

\section{Ternary Isothermal Section}

Two ternary compounds are known in this system: $\operatorname{DyFe}_{12-x} \mathrm{Cr}_{x} \quad(1.6 \leq x \leq 3.0)$, denoted $\tau$ here, has the
$\mathrm{ThMn}_{12}$-type tetragonal structure. $\mathrm{Dy}_{3} \mathrm{Fe}_{29-x} \mathrm{Cr}_{x}$ ( $0.6 \leq$ $x \leq 4.0)$ with the $\mathrm{Nd}_{3}(\mathrm{Fe}, \mathrm{Ti})_{29}$-type of monoclinic structure was found at $1000{ }^{\circ} \mathrm{C}$, but it is not stable at $500{ }^{\circ} \mathrm{C}$ [2009Yao].

With starting metals of $99.9 \% \mathrm{Cr}, 99.9 \% \mathrm{Dy}$, and 99.99\% Fe, [2009Yao] arc-melted 140 alloys in Ar atm. The alloys were given a final anneal at $500{ }^{\circ} \mathrm{C}$ for $150 \mathrm{~h}$ and quenched in water. The phase equilibria were studied mainly with $\mathrm{x}$-ray powder diffraction. The isothermal section at $500{ }^{\circ} \mathrm{C}$ constructed by [2009Yao] is shown in Fig. 1. The ternary phase $\tau$ is present. The Fe-Dy binary compounds $\mathrm{Fe}_{17} \mathrm{Dy}_{2}, \mathrm{Fe}_{23} \mathrm{Dy}_{6}, \mathrm{Fe}_{3} \mathrm{Dy}$, and $\mathrm{Fe}_{2}$ Dy dissolve up to $13,6,5$, and 16 at.\% $\mathrm{Cr}$, respectively. The $\mathrm{Fe}-\mathrm{Cr} \sigma$ phase is not stable at $500{ }^{\circ} \mathrm{C}$.

\section{References}

1993Itk: V.P. Itkin, Cr-Fe (Chromium-Iron), Phase Diagrams of Iron Alloys, H. Okamoto, Ed., ASM International, Materials Park, OH, 1993, p 102-129

2009Yao: Q. Yao, H. Wang, Z. Liu, H. Zhou, and S. Pan, An Investigation of the Dy-Fe-Cr Phase Diagram: Phase Equilibria at $773 \mathrm{~K}, J$. Alloys Compd., 2009, 475, p 286-288

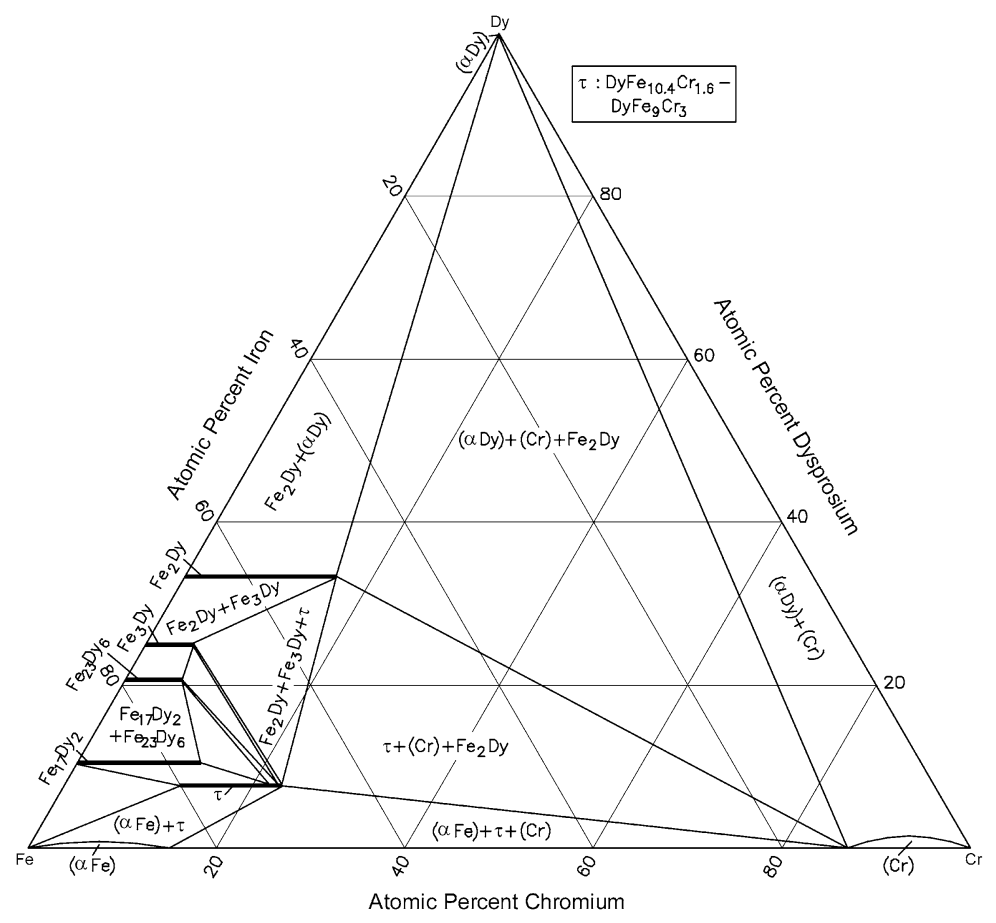

Fig. $1 \mathrm{Cr}-\mathrm{Dy}-\mathrm{Fe}$ isothermal section at $500{ }^{\circ} \mathrm{C}$ [2009Yao]. Narrow two-phase regions are omitted 